\title{
Crystal Phase and Sinterability of Wet-Chemically Derived YAG Powders
}

\author{
Ji-Guang LI, Jong-Heun LEE, Toshiyuki MORI, Yoshiyuki YAJIMA,
} Satoshi TAKENOUCHI and Takayasu IKEGAMI

National Institute for Research in Inorganic Materials, 1-1, Namiki, Tsukuba-shi, Ibaraki 305-0044

\author{
溶液法で調製した前駆体を仮焼して得られる YAG 粉末の結晶相と焼結性 \\ 李 継光·李 鐘欣·森 利之·矢島祥行·竹之内 智·池上隆康 \\ 無機材質研究所, 305-0044 荻城県つくば市並木 1-1
}

\begin{abstract}
Four wet-chemical methods (normal strike co-precipitation, reverse strike co-precipitation, urea homogeneous precipitation, and a modified Pechini process) were adopted in the present work to synthesize the precursor for a sinterable YAG powder. The X-ray diffraction (XRD) results revealed that the phase development of the precursor during calcination and the formation temperature of pure YAG vary among the four methods. The lowest temperatures for pure YAG formation were determined by the XRD method to be $850^{\circ} \mathrm{C}$, $950^{\circ} \mathrm{C}, 1200^{\circ} \mathrm{C}$ and $>1200^{\circ} \mathrm{C}$ for the modified Pechini method, reverse strike co-precipitation, normal strike co-precipitation and urea homogeneous precipitation, respectively. The differences concerning YAG formation among the four methods were explained from the view point of the chemical homogeneity of the precursor. That is, higher chemical homogeneity resulted in the lower temperature of YAG formation. Except the case of modified Pechini method, the sinterability of the YAG powders increased with a decrease in the above temperatures for pure YAG formation because the YAG powder produced from the precursor with higher chemical homogeneity showed smaller particle size and weaker agglomeration. The YAG powder synthesized by the modified Pechini method showed the poorest sinterability due to its extremely hard aggregates caused by the direct pyrolysis of the mother salts. The most sinterable YAG powder, produced by the reverse strike co-precipitation method, densified up to $91.86 \%$ of its theoretical density after sintering at $1520^{\circ} \mathrm{C}$ with a constant heating rate of $8{ }^{\circ} \mathrm{C} / \mathrm{min}$. While the YAG powder synthesized by the modified Pechini method only densified up to $69.2 \%$ of its theoretical density under the same sintering conditions.
\end{abstract}

[Received September 2, 1999; Accepted February 16, 2000]

Key-words : YAG powder, Wet-chemical synthesis, Crystal phase, Sinterability

1. Introduction

Yttrium aluminum garnet (YAG) ceramics are important from the view points of both its optical and mechanical properties. Since YAG single crystal is optically transparent and the dodecahedral sites of its structure can be partially doped or completely substituted with other rare-earth cations such as $\mathrm{Nd}^{5+}, \mathrm{Cr}^{3+}, \mathrm{Eu}^{3+}$, it has been used as solidstate laser material and phosphor powder for cathode ray tubes for more than thirty years. YAG also holds great potential as high-temperature engineering materials. Recent works of Corman $^{1)}$ and Parthasarathy et al. ${ }^{2}$ identified that YAG is the most temperature-resistant material among oxides. At elevated temperatures, YAG shows outstanding strength retainability and exceptionally low creep rates. For example, Corman's work ${ }^{1)}$ on creep behavior of single crystal YAG shows that the creep rate is only $2 \times 10^{-9} \mathrm{~s}^{-1}$ under an applied compressive stress of $100 \mathrm{MPa}$ at $1700^{\circ} \mathrm{C}$, and this rate is almost one magnitude lower than that of the single-crystal $\mathrm{Al}_{2} \mathrm{O}_{3}$ under analogous conditions. Polycrystalline $\mathrm{YAG}$ also exceeds $\mathrm{Al}_{2} \mathrm{O}_{3}$ ceramic in high-temperature creep resistance. At $1400^{\circ} \mathrm{C}$, polycrystalline YAG $(\approx 3 \mu \mathrm{m}$ grain size) stressed at $75.5 \mathrm{MPa}$ exhibits a creep rate of 2.5 $\times 10^{-6} \mathrm{~S}^{-1}$ which is only one third of that of the polycrystalline $\mathrm{Al}_{2} \mathrm{O}_{3}(\approx 3 \mu \mathrm{m}$ grain size $)$ tested under equivalent conditions. $^{2 \text { ) }}$

Practical properties of ceramic materials, however, drastically change with their microstructures which are closely related to the characteristics of starting powders. Development of noble powder processing is one of important steps to fabricate high performance ceramics, including YAG.

Earlier research work ${ }^{3)}$ on YAG preparation through solid-state reaction from mixtures of individual yttria and alumina powders revealed that YAG forms via the following reactions:

$$
\begin{aligned}
& 2 \mathrm{Y}_{2} \mathrm{O}_{3}+\mathrm{Al}_{2} \mathrm{O}_{3} \longrightarrow \mathrm{Y}_{4} \mathrm{Al}_{2} \mathrm{O}_{9}(\mathrm{YAM}) \\
& \quad\left(900-1100^{\circ} \mathrm{C}\right), \\
& \mathrm{YAM}+\mathrm{Al}_{2} \mathrm{O}_{3} \longrightarrow 4 \mathrm{YAlO}_{3}(\mathrm{YAP}) \\
& \quad\left(1100-1250^{\circ} \mathrm{C}\right), \\
& 3 \mathrm{YAP}+\mathrm{Al}_{2} \mathrm{O}_{3} \longrightarrow \mathrm{YAG} \quad\left(1400-1600^{\circ} \mathrm{C}\right) .
\end{aligned}
$$

The temperature in parenthesis indicates within what range the reactions begin. The reaction between alumina and yttria ${ }^{3)}$ occurs by the diffusion of $\mathrm{Al}$ into $\mathrm{Y}_{2} \mathrm{O}_{3}$. The first phase to develop during heat treatment, therefore, is the yttrium-rich YAM phase. This reaction starts at about $900^{\circ} \mathrm{C}$, and as it progresses, the $\mathrm{Al}$ continues to react with the $\mathrm{Y}_{2} \mathrm{O}_{3}$ but also diffuses into YAM to form YAP, starting at a temperature of about $1100^{\circ} \mathrm{C}$. Finally, the $\mathrm{Al}_{2} \mathrm{O}_{3}$ reacts with YAP at approximately $1400^{\circ} \mathrm{C}$ to produce YAG. Since the kinetics of Reaction (3) is quite low, unreacted $\mathrm{Al}_{2} \mathrm{O}_{3}$ and YAP sometimes remain after heat treatment due to insufficient temperature and holding time. Some studies have shown that $\mathrm{Al}_{2} \mathrm{O}_{3}$ and YAP will remain in the sample unless the sample is heated at $1600^{\circ} \mathrm{C}$ for $20 \mathrm{~h}$ or heated to $1700^{\circ} \mathrm{C}$.

So in contrast with the case of single oxides such as $\mathrm{Al}_{2} \mathrm{O}_{3}$, $\mathrm{Y}_{2} \mathrm{O}_{3}$ and $\mathrm{MgO}$, good mixing of the starting materials must be made in the processing of YAG to achieve not only excellent chemical homogeneity of the product but also a highly sinterable powder.

It has long been recognized that wet-chemical process offers considerable advantages of good mixing of the starting material and excellent chemical homogeneity of the final product. Several kinds of wet-chemical methods, aimed at lowering phase formation temperature and achieving higher phase purity, have been employed successfully in the production of YAG materials. These methods include 
hydroxide co-precipitation, ${ }^{4)}$ sol-gel of metal alkoxides, ${ }^{5)}$ hydrothermal treatment, ${ }^{6}$ glycothermal treatment, ${ }^{7)}$ pyrolysis of metal nitrate mixtures, ${ }^{8)}$ combustion synthesis ${ }^{9)}$ and the Pechini process. ${ }^{10)}$ However, results concerning the sequence of phase development, the phases that exist, and the temperatures at which the processes occur are still controversial. Thus there remain many issues about relations between sinterability and the processing of YAG powder which governs the packing regularity of particles. To ascertain relations between conditions of wet-chemical process and sinterability of the YAG powders, in the present study, four wet-chemical methods, which are normal strike coprecipitation (NSC), reverse strike co-precipitation (RSC), urea homogeneous precipitation (UHP) and a modified Pechini process (MPP), were used to prepare YAG precursors. The phase development of these precursors during heat treatment was studied in detail by X-ray diffraction (XRD) method, and the sinterability of the YAG powders was investigated by sintering at a constant rate of heating in air.

\section{Experimental}

\subsection{Starting materials}

Aluminum nitrate nonahydrate $(>98.0 \%$ purity, Wako Pure Chemical Industries, Ltd., Osaka, Japan), yttrium nitrate hexahydrate ( $>99.99 \%$ purity, Kanto Chemical Co., Inc., Tokyo, Japan), citric acid monohydrate (>99.5\% purity, Wako Pure Chemical Industries, Ltd., Osaka, Japan), 25\% ammonia water ( $>98.0 \%$ purity, Wako Pure Chemical Ind., Ltd., Osaka, Japan) and urea (ultra pure, Schwarz/Mann Biotech, Ohio, U.S.A.) were used as starting materials. All these chemicals were used as received without further purification.

The stock solution of mother salts was made by dissolving aluminum and yttrium nitrates in distilled water. Contents of the crystallized water in aluminum and yttrium nitrates were checked beforehand by TG analysis from the weight loss after each salt was calcined to $1200^{\circ} \mathrm{C}$ and held for $1 \mathrm{~h}$. To ensure that yttrium and aluminum ions would be mixed at the YAG stoichiometry of $3: 5$ molar ratio, aluminum and yttrium contents of the solution were further analyzed by the ICP (inductively coupled plasma) spectrophotometric technique and adjusted. A $2 \mathrm{~N}$ ammonia water, obtained by diluting the $25 \%$ ammonia water, was used as the precipitant for hydroxide co-precipitation.

\subsection{Powder preparation}

\subsubsection{Co-precipitation methods}

Co-precipitation can be performed by the NSC method (adding basic solution to the acidic phase) or by the RSC method (addition of acidic solution to the basic phase). The main difference between these two methods is the rate at which $\mathrm{pH}$ of the salt solution changes as a function of time. For comparison, both NSC and RSC methods were examined in this work to prepare YAG precursors.

Precipitation processes were conducted at room temperature on a magnetic stirrer. Concentration of the mother salt solution was $0.15 \mathrm{M}$ in aluminum ion. For NSC process, the $2 \mathrm{~N}$ ammonia water was dripped at a speed of $2 \mathrm{ml} / \mathrm{min}$ from a burette into rapidly stirred salt solution contained in a beaker until a $\mathrm{pH}$ value of 10 was reached. The slurry was filtered using a suction filter after being stirred for another $30 \mathrm{~min}$ for homogenization. The resultant precipitate cake was then ultrasonically dispersed into distilled water and the suspension was filtered again. The above dispersing and filtering processes were repeated four times to completely remove by-products of the precipitation reaction. Finally, the precipitate was rinsed with anhydrous ethanol to replace water in the precipitate and prevent severe agglomeration of the particles during drying process which was performed at room temperature under flowing nitrogen for $24 \mathrm{~h}$. The dried precipitate was crushed with zirconia pestle and motar and calcined at various temperatures in the range of $500-1200^{\circ} \mathrm{C}$ under flowing oxygen for $1 \mathrm{~h}$ to produce oxide powders. The RSC process was similar to the NSC process except that the salt solution was added to the ammonia water.

\subsubsection{UHP method}

UHP process was performed on a hot plate with magnetic stirrer. Proper amount of the stock solution was diluted with deionized water to a concentration of $0.0125 \mathrm{M}$ in aluminum ion and stored in a $1000 \mathrm{ml}$ beaker. Urea was then dissolved into the solution to make a concentration of $0.2 \mathrm{M}$. The mixed solution, after being kept at room temperature under stirring for $24 \mathrm{~h}$ for homogenization, was heated to $90^{\circ} \mathrm{C}$ and kept for $24 \mathrm{~h}$ to effect precipitation. To avoid temperature gradient, the beaker was wrapped with aluminum foil. The resultant dispersion was filtered after cooling down to the room temperature and treated by the same way as described in Section 2.2.1.

\subsubsection{MPP method}

The stock solution with a concentration of $0.5 \mathrm{M}$ in aluminum ion was used directly for YAG synthesis without further dilution. Citric acid monohydrate, used as a chelating reagent, was added to the salt solution under stirring. The molar content of citric acid was chosen twice that of the total metal cations.

The mixed solution was homogenized under stirring for $24 \mathrm{~h}$ at room temperature before heating to $70^{\circ} \mathrm{C}$ and holding at this temperature to evaporate off water. Due to the complexing effect of the citric acid, no precipitation occurred during the evaporation process. After the first tint of brownish color appeared, which was caused by the decomposition of nitrates, the sticky melt was rapidly heated to $180^{\circ} \mathrm{C}$ and kept at this temperature until no nitrogen oxide gas released. The resultant brownish colored powder was used as the precursor, and further decomposition of the precursor was conducted in a tube furnace at various temperatures in the range of $500-1100^{\circ} \mathrm{C}$ for $1 \mathrm{~h}$ under flowing oxygen gas.

\subsection{Powder characterization}

Phase identification of the powder was performed by XRD method on a Philips PW1700 X-ray diffractometer using $\mathrm{Cu} \mathrm{K} \alpha$ radiation in the range of $2 \theta=10-70^{\circ}$ at a scanning rate of $2 \theta=1.5^{\circ}$ per minute.

Morphology of the YAG powder was observed by scanning electron microscopy (SEM) (Model S-5000, Hitachi, Ltd., Tokyo, Japan). Samples were ultrasonically dispersed into acetone, and the suspensions were spread on the surfaces of silicon plates. All samples were coated with a thin layer of osmium metal for conductivity before observation.

\subsection{Compaction and sintering of the YAG powders}

Sintering under constant rate of heating was made to investigate sinterability of the YAG powders. For compaction, powders were first dry pressed manually into small cylinders with a diameter of $6 \mathrm{~mm}$ and a length of $4-6 \mathrm{~mm}$ in a tungsten carbide die and then isostatically pressed to 200 MPa pressure. Sintering was conducted in air using a TMA unit (thermal mechanical analyzer, TMA 1700, Rigaku Corp., Japan) to $1520^{\circ} \mathrm{C}$ with a heating rate of $8^{\circ} \mathrm{C} / \mathrm{min}$ and a cooling rate of $15^{\circ} \mathrm{C} / \mathrm{min}$. The densities, $\rho$, at all temperatures were determined from the green density, $\rho_{0}$, and the measured linear shrinkage, $\Delta L / L_{0}$, using the following equation:

$$
\rho=\rho_{0} /\left(1-\Delta L / L_{0}\right)^{3}
$$

where $L_{0}$ is the initial length of the sample and $\Delta L=L_{0}-L$, where $L$ is the instantaneous sample length. Green density of the powder compact was calculated from its weight and geometric dimensions. Relative sintered density was ob- 
tained by taking the theoretical density of $\mathrm{YAG}^{5)}$ as $4.55 \mathrm{~g} /$ $\mathrm{cm}^{3}$.

\section{Results and discussion}

3.1 Phase evolution of the precursor

\subsubsection{NSC method}

$\mathrm{X}$-ray diffraction patterns of the precursor synthesized by NSC method and its calcination products were given in Fig. 1. The precursor is essentially amorphous, which retains even after calcination to $800^{\circ} \mathrm{C}$. At $900^{\circ} \mathrm{C}$, instead of YAM, hexagonal YAP ${ }^{11)}$ and $\mathrm{YAG}^{12)}$ crystallized simultaneously from the amorphous matrix with YAP as the major one. Although the amount of YAG is small at this temperature, most of the peaks reported for $\mathrm{YAG}^{12}$ were found. Raising calcination temperature increased the amount of YAG phase while decreased the amount of YAP phase. YAP phase disappeared after heat treatment at 1100 ${ }^{\circ} \mathrm{C}$ for $1 \mathrm{~h}$. Another distinct feature of the XRD patterns is that YAM phase ${ }^{13)}$ appeared at $1000^{\circ} \mathrm{C}$ after the formation of YAP, but this YAM phase disappeared by $1200^{\circ} \mathrm{C}$. Pure YAG powder was obtained by calcining at temperatures $\geq$ $1200^{\circ} \mathrm{C}$.

The relatively high temperature and complex route of YAG formation was caused by the poor chemical homogeneity of the precursor. The stock solution of mother salts for $\mathrm{YAG}$ synthesis contains both $\mathrm{Al}^{3+}$ and $\mathrm{Y}^{3+}$ cations. When the solution was used for co-precipitation by NSC method, different $\mathrm{pH}$ values at which $\mathrm{Al}^{3+}$ and $\mathrm{Y}^{3+}$ cations precipitate influenced the chemical homogeneity of the

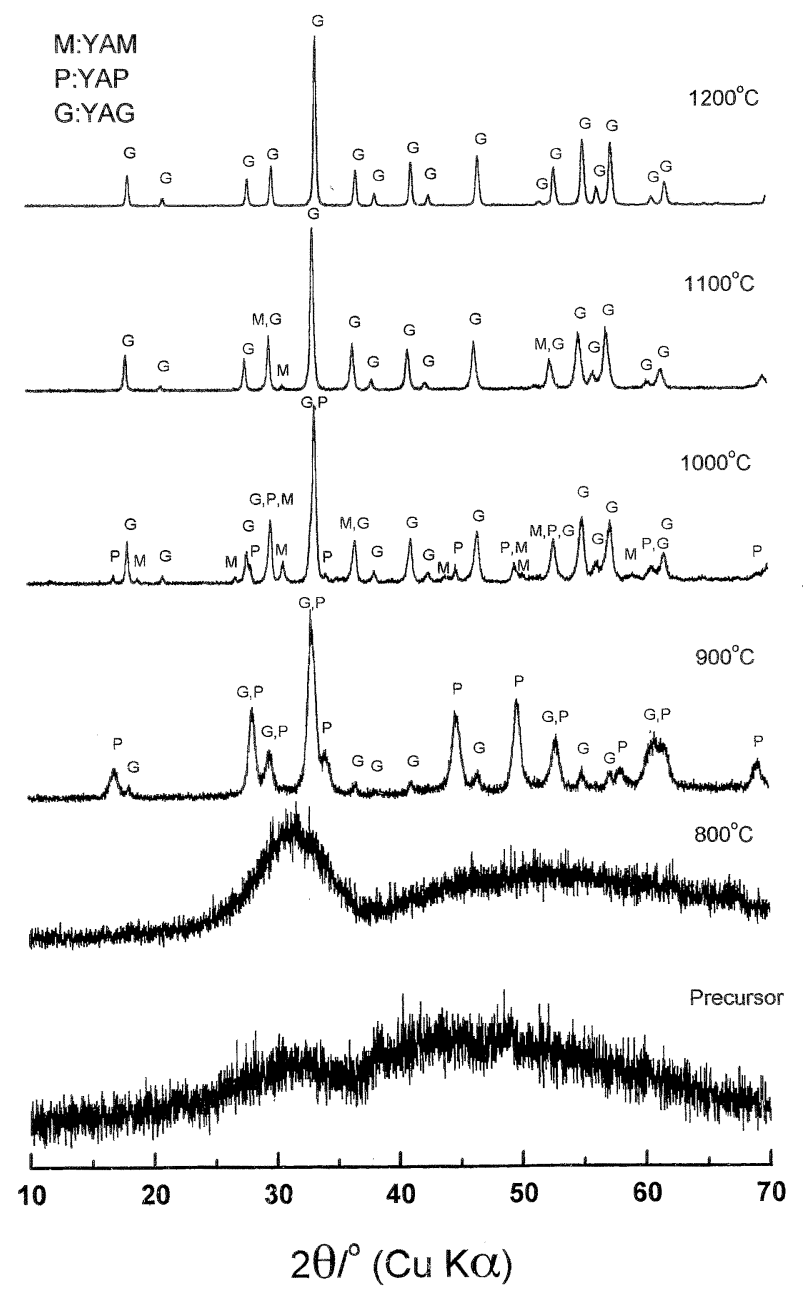

Fig. 1. XRD patterns of the powders produced by NSC method. precursor. Vrolijk et al. ${ }^{14}$ investigated the precipitation processes of aluminum nitrate and yttrium nitrate separately using sodium hydroxide solution as a precipitant. They found that the precipitation of $\mathrm{Al}^{3+}$ ions started from a $\mathrm{pH}$ value of 3.5 and ended at 5.0, while the precipitation of $\mathrm{Y}^{3+}$ ions started only from a much higher $\mathrm{pH}$ value of 7.0 . So the precursor synthesized by NSC method was a mixture of hydroxides since $\mathrm{pH}$ value of the salt solution increased gradually with the gradual addition of ammonia water and aluminum and yttrium hydroxides precipitated separately within their own ranges of $\mathrm{pH}$ value. The adding rate of ammonia water was expected to affect the chemical homogeneity of the precipitate. However; the low adding rate $(2 \mathrm{ml} / \mathrm{min})$ used in the present work is not favorable for achieving high chemical homogeneity. Based on this separate precipitation phenomena, the composition of the precursor can be roughly expressed as $\left[5 \mathrm{Al}(\mathrm{OH})_{3}+\right.$ $\left.3 \mathrm{Y}(\mathrm{OH})_{3}\right]$. The poor chemical homogeneity of the precursor caused YAG phase to form at relatively high temperatures $\left(\geq 1200^{\circ} \mathrm{C}\right)$ via both YAM and YAP intermediate phases, since the YAG formation proceeds by the diffusion of aluminum into yttria while poor chemical homogeneity indicates long diffusion paths.

\subsubsection{RSC method}

XRD patterns (Fig. 2) of the powders produced by RSC method are quite similar to those of NSC derived powders up to $900^{\circ} \mathrm{C}$ : the precursor remains amorphous up to $800^{\circ} \mathrm{C}$ and YAG began to crystallize from the amorphous matrix at $900^{\circ} \mathrm{C}$ with the presence of YAP phase. However, distinct difference appeared between these two precursors above $900^{\circ} \mathrm{C}$ concerning phase constituents and phase evolution sequence. For the RSC derived precursor, YAG, rather than $\mathrm{YAP}$, is the major crystalline phase at $900^{\circ} \mathrm{C}$, and pure $\mathrm{YAG}$

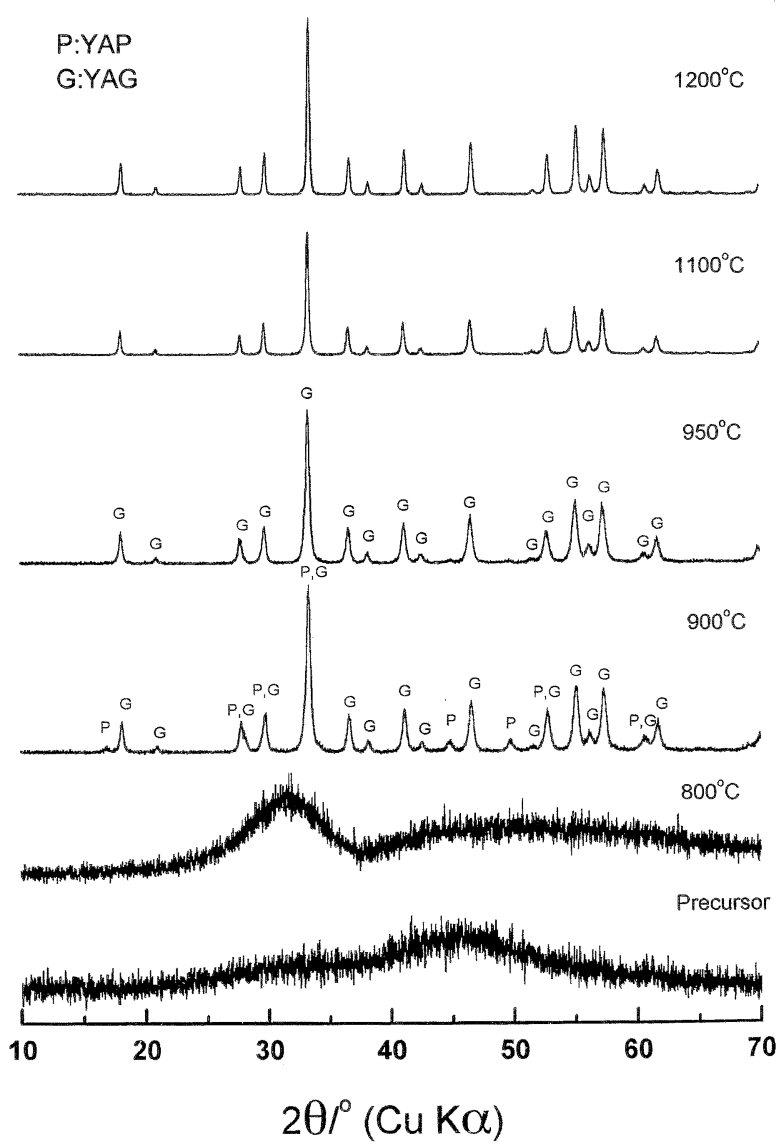

Fig. 2. XRD patterns of the powders produced by RSC method. 
powder can be produced at $950^{\circ} \mathrm{C}$, which is bout $250^{\circ} \mathrm{C}$ lower than that of the NSC derived precursor. No YAM phase was detected during calcination.

The above XRD results indicated that the RSC derived precursor possessed higher chemical homogeneity compared with the NSC derived precursor. This is because the dropwise addition of the salt solution to the base $\left(\mathrm{NH}_{4} \mathrm{OH}\right)$ during RSC process resulted in an almost instantaneous increase in the $\mathrm{pH}$, well past the precipitation values of both the salts, and chemical inhomogeneity of the precipitate was limited to the extent of one drop of the salt solution. That is, each particle of the precursor contains both $\mathrm{Y}$ and $\mathrm{Al}$ elements which are mixed at $3: 5$ molar ratio and nearly on the atomic level. In this case, the chemical composition of the precursor can be approximately expressed as $\left(\mathrm{Y}_{3}, \mathrm{Al}_{5}\right)$ $(\mathrm{OH})_{24}$. The intimate mixing of aluminum and yttrium elements shortened the diffusion path, allowing YAG to form at lower temperatures via a simpler route.

\subsubsection{UHP method}

Precursor prepared by UHP method underwent a quite complex phase evolution process during heating, as seen in Fig. 3. The as-prepared precursor is poorly crystallized and makes it difficult for us to perform phase identification by XRD method.

Crystallization of the precursor started from $900^{\circ} \mathrm{C}$, at which YAM and YAP phases emerged simultaneously. These two intermediate phases persisted to high temperatures: $1050^{\circ} \mathrm{C}$ for YAP and $1200^{\circ} \mathrm{C}$ for YAM. Although the formation of $Y A G$ started from $1000^{\circ} \mathrm{C}$, pure $Y A G$ powder still could not be obtained at $1200^{\circ} \mathrm{C}$.

Compared with NSC method, the UHP derived precursor showed slower kinetics of transformation to YAG. This phenomena can also be explained from the view point of

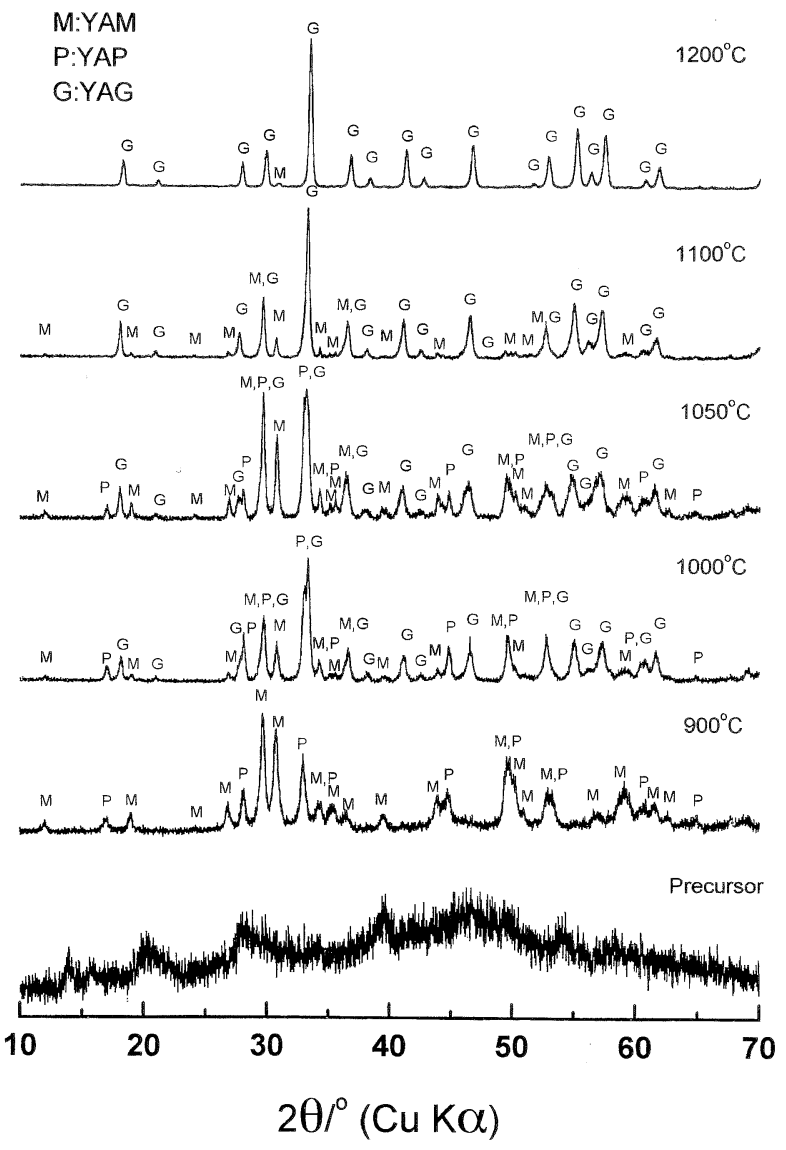

Fig. 3. XRD patterns of the powders produced by UHP method. chemical homogeneity of the precursor by considering the UHP process. A key feature of the UHP method is the much slower introduction of precipitation participating ligands into the salt solution. ${ }^{15)}$ Since supersaturation of such ligands achieved by hydrolysis of urea is never very high, it is reasonable to predict that precipitation of aluminum and yttrium ions was clearly separated into two stages. That is, after the precipitation of aluminum compound finished, yttrium compound started to precipitate at higher $\mathrm{pH}$ values. Unlike the cases of NSC and RSC processes, yttrium most likely precipitated as basic carbonate ${ }^{15}$ ) during UHP process. Even though, the $\mathrm{pH}$ value for the formation of yttrium basic carbonate (between 5.5 and 6.0) is still higher than that for the precipitation of aluminum ions. Therefore, the precursor precipitate derived from UHP method has even poor chemical homogeneity, resulting in higher temperature of YAG formation and more complex process of phase development.

3.1.4 MPP method

XRD patterns of the powders derived from MPP method were given in Fig. 4. Compared with the above three methods, this method produced pure YAG phase more easily and directly. YAG started to crystallize from the amorphous matrix at $800^{\circ} \mathrm{C}$ without the formation of YAM and YAP phases, and pure YAG was obtained at $850^{\circ} \mathrm{C}$. As calcination temperature increased towards $1100^{\circ} \mathrm{C}$, crystallinity of the YAG phase improved.

The direct crystallization of YAG suggests that aluminum and yttrium elements must have been fixed at atomic level by the complexing of citric acid. The atomic level mixing of elements shortened the diffusion path to reach YAG compo-

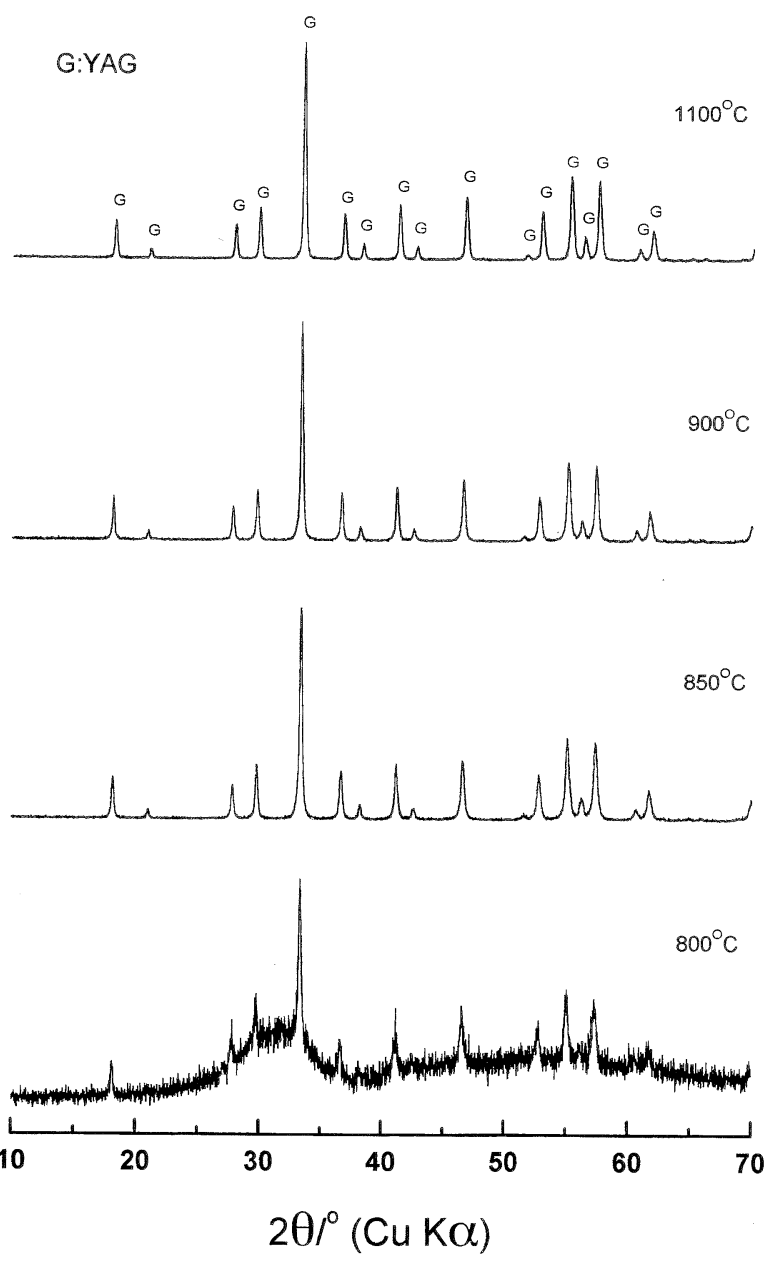

Fig. 4. XRD patterns of the powders produced by MPP method. 
sition and, therefore, pure YAG formed directly without the formation of intermediate YAM and YAP phases.

\subsection{Powder morphology and sintering}

Four kinds of powders were used for sintering study, and hereafter they were simply referred to as P1, P2, P3 and P4, respectively. The synthesis conditions of these powders were listed as follows: P1: RSC method, calcined at $950^{\circ} \mathrm{C}$; P2: NSC method, calcined at $1200^{\circ} \mathrm{C}$; P3: UHP method, calcined at $1200^{\circ} \mathrm{C} ; \mathrm{P} 4: \mathrm{MPP}$ method, calcined at $900^{\circ} \mathrm{C}$. As seen from the XRD results (Fig. 1 to Fig. 4), these calcination temperatures were chosen to be the critical temperatures at which pure YAG powders can be obtained. The holding time at the calcination temperatures for all powders was $1 \mathrm{~h}$. After calcination, all powders are pure YAG except that P3 contains a very small amount of YAM phase. We have two reasons for this choice of calcination temperatures: the first reason is that higher calcination temperatures will inevitably cause considerable growth and hard agglomeration of powder particles, which will decrease the sinterability of the powders; the second reason is that the powders calcined at lower temperatures contain second phases (see Fig. 1 to Fig. 4) and are chemically inhomogeneous, while chemical inhomogeneity ${ }^{16)}$ of the powder affects negatively on densification in final stage sintering. Green density, as determined from the weight and geometric dimensions of the green compact, was $39.08 \%, 47.47 \%$, $46.74 \%$ and $48.35 \%$ for $\mathrm{P} 1, \mathrm{P} 2, \mathrm{P} 3$ and $\mathrm{P} 4$, respectively.
Figure 5 shows SEM morphologies of the YAG powders used for sintering study. A common feature of the precipitation derived powders (P1, P2 and P3) is that they all have two kinds of microstructures: relatively discrete particles and aggregates. However, different preparation methods caused noticeable differences in the particle size and the dispersity of these powders. Compared with P2 and P3, P1 powder (Fig. 5(a)) shows the highest dispersity as well as the smallest particle and aggregate size. Although the primary particle size is quite similar for P2 and P3, the nature of agglomeration is quite different. The aggregates in P2 powder (Fig. 5(b)) are relatively loosely-compacted, while those of P3 (Fig. 5(c)) are larger-sized $(\approx 2 \mu \mathrm{m})$ and more densely sintered. P4 powder showed a quite different morphology (Fig. 5(d)) from those of the other three powders. It is mainly composed of irregularly shaped large particles. Higher magnification (Fig. 5 (e)) revealed that these "particles" are essentially hard aggregates formed by sintering of nano-sized primary particles.

Figure 6 presented the relative density versus temperature during sintering under constant rate of heating. Rapid densification of the green compacts commenced at $1300^{\circ} \mathrm{C}$ for all powders except P1 which started from a lower temperature of $1200^{\circ} \mathrm{C}$. After TMA measurement, the relative density of $\mathrm{P} 1, \mathrm{P} 2, \mathrm{P} 3$ and $\mathrm{P} 4$ powder is $91.86 \%, 88.18 \%$, $70.63 \%$ and $69.2 \%$, respectively. Sinterability of a powder is strongly influenced by its particle size and agglomeration
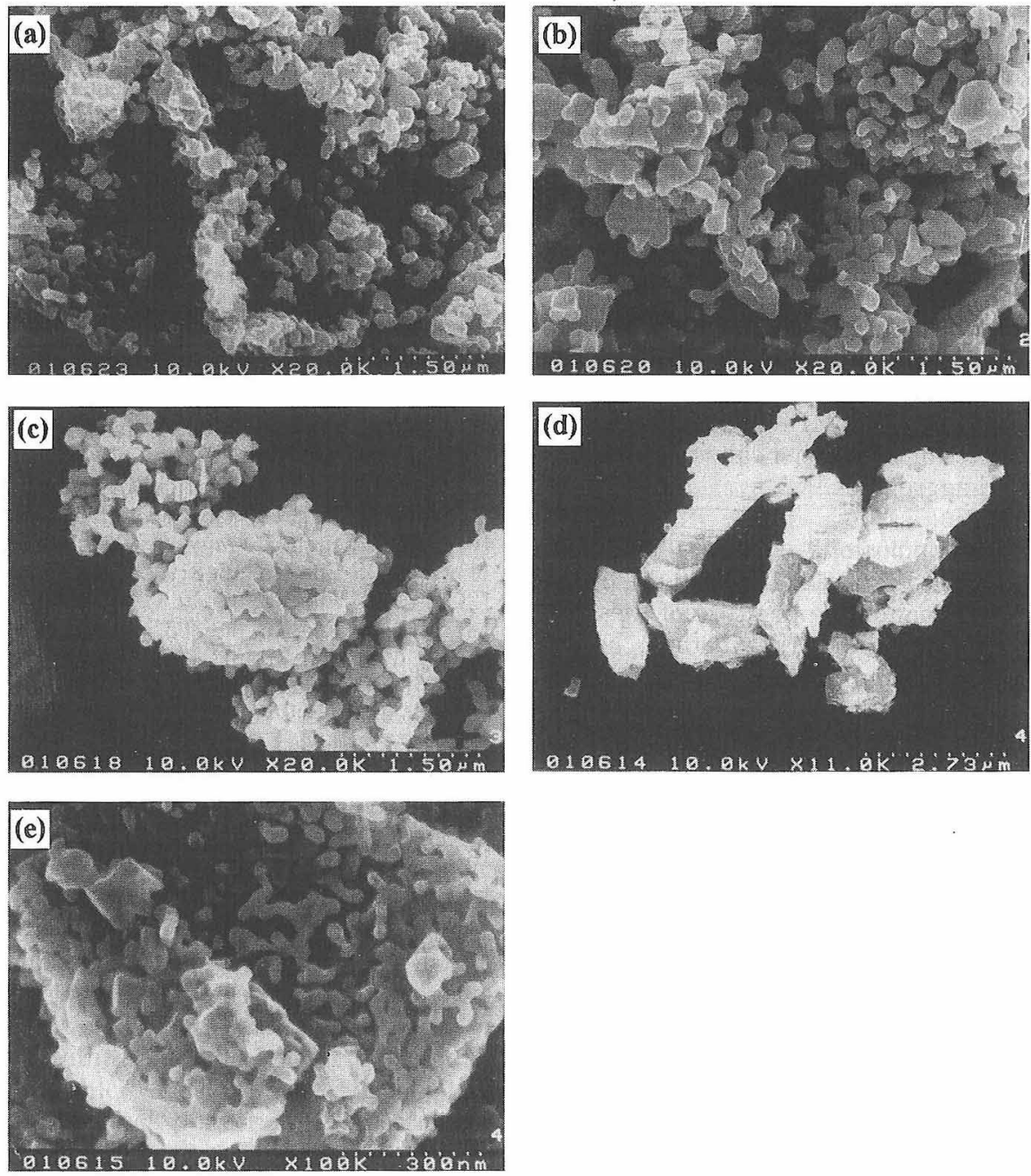

Fig. 5. SEM morphologies of the YAG powders obtained by calcination, the holding period is $1 \mathrm{~h}$ : (a) RSC method, calcined at $950^{\circ} \mathrm{C}$, (b) NSC method, calcined at $1200^{\circ} \mathrm{C}$, (c) UHP method, calcined at $1200^{\circ} \mathrm{C}$, (d) MPP method, calcined at $900^{\circ} \mathrm{C}$ and (e) MPP method, calcined at $900^{\circ} \mathrm{C}$, observed under higher magnification. 


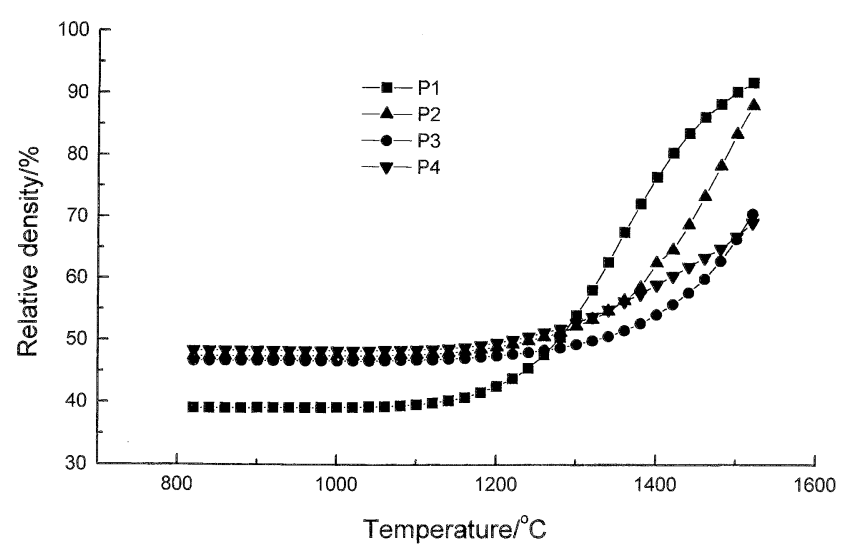

Fig. 6. Relative density versus temperature under sintering at a constant heating rate of $8{ }^{\circ} \mathrm{C} / \mathrm{min}$ in air.

state. From this point of view, the above sintering results are consistent with the SEM observations, that is, powders of less-agglomeration and finer particle size showed better sinterability.

Sinterability of the YAG powders can also be related to the chemical homogeneity of the precursors except P4, and the YAG powder from a precursor with higher chemical homogeneity showed better sinterability. This is because the precipitation derived precursors are composed of particles, and the precursor with higher chemical homogeneity requires less inter-particle diffusion to reach the YAG composition during calcination, which lessens particle growth and the formation of connections between particles (aggregation). Besides, higher chemical homogeneity enables the precursor to convert to pure YAG at lower temperatures, which avoids the rapid particle growth and the further formation of hard agglomerates due to the inter-particle sintering at high calcination temperatures. Therefore, the YAG powder from a precursor with higher chemical homogeneity had smaller particle size, less-agglomeration and better sinterability. The severe aggregation of $\mathrm{P} 4$ powder has a different origin, and it was caused by the MPP method itself during which bulky crystallites of the mother salts directly converted to large and hard aggregates. ${ }^{17)}$

\section{Conclusions}

Chemical homogeneity has dramatic effects on the phase evolution and the YAG formation temperature of the wetchemically derived precursors. For MPP method, nearly atomic level mixing of $\mathrm{Y}$ and $\mathrm{Al}$ elements was achieved in the precursor due to the complexing of citric acid, and the precursor transformed to pure YAG at $850^{\circ} \mathrm{C}$ without the formation of intermediate YAM and YAP phases. For the other three methods, different $\mathrm{pH}$ values for the precipitation of $\mathrm{Al}$ and $\mathrm{Y}$ ions are responsible for the chemical inhomogeneity in the precursors. NSC method can only produce a mixture of aluminum and yttrium hydroxides, and the relatively poor chemical homogeneity of the precursor caused YAG to form at temperatures as high as $1200^{\circ} \mathrm{C}$ via both YAM and YAP phases. RSC method has the advantage of confining such kind of inhomogeneity to the volume of one drop of the salt solution. With improved chemical homogeneity, the precursor transformed to pure YAG at $950^{\circ} \mathrm{C}$ with YAP as the only intermediate phase. The UHP method derived precursor is even inhomogeneous in chemical composition when compared with that of the precursor produced by NSC method, since the hydrolysis of urea, and hence the introduction of precipitant to the salt solution, is very slow. So the UHP derived precursor underwent much more complex phase transformations during heat treatment, and could not transform to pure YAG even after calcination at $1200^{\circ} \mathrm{C}$.

Sintering at constant rate of heating indicated that the $\mathrm{RSC}$ derived YAG powder has the highest sinterability. It densified up to $91.86 \%$ of its theoretical density after heating at $1520^{\circ} \mathrm{C}$ with a constant heating rate of $8{ }^{\circ} \mathrm{C} / \mathrm{min}$. While the powder produced by the modified Pechini method only densified up to $69.2 \%$ under the same conditions, showing the poorest sinterability. Agglomeration state and particle size are mainly responsible for the sinterability of the present YAG powders.

Acknowledgment One of the authors, Ji-Guang Li, would like to express his thanks to JISTEC/JST of Japan for an STA fellowship.

\section{References}

1) G. S. Corman, Ceram. Eng. Sci. Proc., 12, 1745-66 (1991).

2) T. A. Parthasarathy, T. Mah and K. Keller, J. Am. Ceram. Soc., 75, 1756-59 (1992).

3) V. B. Glushkova, V. A. Krzhizhanovskaya, O. N. Egorova, Yu. P. Udalov and L. P. Kachalova, Inorg. Mater. (Eng. Transl.), 19, 80-84 (1983).

4) V. B. Glushkova, O. N. Egorova, V. A. Krzhizhanovskaya and K. Yu. Merezhinskii, Inorg. Mater. (Eng. Transl.), 19, 1015-18 (1983).

5) R. Manalert and M. N. Rahaman, J. Mater. Sci., 31, 3453-58 (1996).

6) T. Takamori and L. David, Am. Ceram. Soc. Bull., 65, 1282-86 (1986).

7) M. Inoue, H. Otsu, H. Kominami and T. Inui, J. Am. Ceram. Soc., 74, 1452-54 (1991).

8) D. R. Messier and G. E. Gazza, Am. Ceram. Soc. Bull., 51, 692-97 (1972).

9) L. E. Shea, J. McKittrick, O. A. Lopez and E. Sluzky, J. Am. Ceram. Soc., 79, 3257-65 (1996).

10) C. D. Veitch, J. Mater. Sci., 26, 6527-32 (1991).

11) JCPDS File No. 16-219.

12) JCPDS File No. 33-40.

13) JCPDS File No. 34-368.

14) J. W. G. A. Vrolijk, J. W. M. M. Willems and R. Metselaar, "The Proceedings of the First European Ceramic Society Conference," Vol. 1, Ed. by G. De With, R. A. Terpatra and R. Metselaar, Elsevier Science Publishers, Essex, England (1989) pp. 105-08.

15) D. Sordelet and M. Akinc, J. Colloid \& Interface Sci., 122 47-59 (1988).

16) T. Ikegami, K. Kotani and K. Eguchi, J. Am. Ceram. Soc., 70 , 885-90 (1987)

17) S. Kato, J. Ceram. Soc. Japan (Yogyo-Kyokai-Shi), 84, 1101-08 (1976) [in Japanese]. 